\title{
RECOBRIMENTOS COMESTÍVEIS NA CONSERVAÇÃO PÓS-COLHEITA DE 'MEXERICA-DO-RIO'
}

\author{
DANIELLE FABÍOLA PEREIRA DA SILVA², DALMO LOPES DE SIQUEIRA ${ }^{3}$, \\ DIERLEI DOS SANTOS ${ }^{4}$, DANIEL LUCAS MAGALHÃES MACHADO 5 , \\ LUIZ CARLOS CHAMHUM SALOMÃO ${ }^{3}$
}

RESUMO - Objetivou-se avaliar o efeito de diferentes concentrações de fécula de mandioca na conservação pós-colheita de frutos de 'Mexerica-do-Rio' armazenados em temperatura ambiente. Os frutos, colhidos no estádio de maturação fisiológica no pomar experimental da UFV, foram selecionados, higienizados,imersos em suspensões de fécula de mandioca a $0 ; 2 ; 3$ e 4\% (p.v), acrescidas de 0,5 mL.L $\mathrm{L}^{-1}$ de óleo mineral por 5 minutos e armazenados a $21,0 \pm 1,0^{\circ} \mathrm{C}$ e $85 \pm 5 \%$ UR, por até 12 dias, sendo avaliados a cada quatro dias. Houve perda de massa fresca em todos os tratamentos, mais drástica naquele onde não houve aplicação de biofilme, sendo que essa perda de massa refletiu à redução no teor de suco. Constatou-se redução significativa do conteúdo de vitamina $\mathrm{C}$ e acidez titulável, com exceção desse último quando se utilizou a maior dose de fécula.

Termos para indexação: Citrus deliciosa., fécula de mandioca, qualidade.

\section{EDIBLE COATINGS ON POSTHARVEST LIFE OF 'MEXERICA-DO-RIO’}

\begin{abstract}
The aim was to evaluate the effect of different doses of cassava starch in postharvest fruit of 'Mexerica-do-Rio' storage at room temperature. The fruits were harvested at physiological maturity in the experimental orchard at UFV, and were selected, cleaned and then immersed in suspensions of cassava starch at doses of $0,2,3$ and $4 \%\left(\mathrm{~g} . \mathrm{v}^{-1}\right)$, plus $0.5 \mathrm{~mL} \cdot \mathrm{L}^{-1}$ of mineral oil for 5 minutes and stored at $21.0 \pm 1.0$ ${ }^{\circ} \mathrm{C}$ and relative humidity of $85 \pm 5 \%$, for 12 days, and were evaluated every four days. There was a fresh mass loss in all treatments, however more drastic when no application of biofilm was made. The mass loss reflected in the juice content reduction. It was observed significant reduction in the vitamin $\mathrm{C}$ content and acidity, except for the latter, when using the higher dose of starch.
\end{abstract}

Index terms: Citrus deliciosa Ten., Cassava starch, quality.

\section{INTRODUÇÃO}

A Mexerica-do-Rio (Citrus deliciosa Ten.) é bastante popular nas regiões Sudeste e Sul do Brasil, principalmente pelo seu aroma e sabor acentuados. Os frutos são de tamanho pequeno a médio, a casca é fina, lisa e brilhante, sendo facilmente removida. É considerado um fruto de meia-estação, sendo a colheita concentrada basicamente nos meses de maio a junho (NASCIMENTO et al., 2007).

Devido à colheita ser sazonal, há interesse comercial em estender a oferta desse fruto para o consumidor durante um período mais prolongado. Todavia, as frutas cítricas apresentam perda de qualidade visual durante o armazenamento devido à excessiva perda de água (HENRIQUE et al., 2007). Para contornar tal situação, a modificação da atmosfera pela utilização de filmes permite a redução da perda de massa e a manutenção da qualidade de frutos (NUNES et al., 2004).

O uso de películas (filmes) comestíveis ou biofilmes é uma tecnologia recente, que tem como matéria-prima os derivados da amilose, da celulose ou do colágeno, podendo ser removidas com água ou ingeridas juntamente com o produto protegido e apresentam-se como produto comercial de baixo custo (SCANAVACA JÚNIOR, 2007). Os biofilmes comestíveis, que têm o amido como biopolímero

\footnotetext{
${ }^{1}$ Trabalho Sinfruit 061 - Simpósio Internacional de Fruticultura - Avanços na Fruticultura (17 a 21 Outubro)

${ }^{2}$ Eng. Agrônoma, Pós-Doutoranda (Bolsista PNPD - CAPES) - Departamento de Fitotecnia - Universidade Federal de Viçosa - Av. PH Rolfs s/n - Câmpus Universitário - Viçosa-MG - danieele@ufv.br

${ }^{3}$ Eng. Agrônomo, Doutor - Departamento de Fitotecnia - Universidade Federal de Viçosa- Av. PH Rolfs s/n - Câmpus Universitário Viçosa-MG. Bolsista Produtividade CNPq - Autor para correspondência: 1salomao@ufv.br, siqueira@ufv.br

${ }^{4}$ Estudantes de Doutorado - Departamento de Fitotecnia - Universidade Federal de Viçosa - Av. PH Rolfs s/n - Câmpus Universitário - Viçosa-MG. E-mail: dierlei@vicosa.ufv.br

${ }^{5}$ Estudante de Agronomia - Estudante Doutorado - Departamento de Fitotecnia - Universidade Federal de Viçosa -Av. PH Rolfs s/n Câmpus Universitário - Viçosa-MG
} 
para sua formação, começam a ser estudados de forma mais intensa, e têm a fécula de mandioca selecionada como a matéria-prima mais adequada para sua elaboração, por formar películas resistentes e transparentes, constituir barreiras eficientes à perda de água e proporcionarem bom aspecto e brilho intenso, tornando as frutas comercialmente atrativas (LEMOS et al., 2007).

Esta pelicula não é tóxica, pode ser ingerida com a fruta ou facilmente removida com água e tem baixo custo (HENRIQUE et al., 2007). De acordo com Chitarra e Chitarra (2005), os biofilmes provocam a redução de perda de água e da síntese de etileno, diminuindo a atividade respiratória, e retardando a senescência.

Diversos trabalhos foram realizados com resultados positivos, especialmente para o controle da perda de massa e prolongamento da vida útil pós-colheita de morango, laranja, goiaba, pêssego e acerola (MACIEL et al., 2004; OLIVEIRA; CEREDA, 2003; OLIVEIRA; CEREDA, 1999). Todavia, não foi encontrado na literatura consultada o uso de biofilmes para a conservação pós-colheita de mexericas.

Este trabalho objetivou avaliar o efeito de diferentes concentrações de fécula de mandioca na vida útil pós-colheita e manutenção da qualidade de frutos Mexerica-do-Rio (Citrus deliciosa Ten.) armazenados em ambiente, a $21^{\circ} \mathrm{C}$ e $85 \%$ UR.

\section{MATERIAL E MÉTODOS}

Frutos fisiologicamente maduros, com massa de $325,79 \pm 22,19 \mathrm{~g}$, e cascas de cor amarela, foram obtidos em pomar experimental da Universidade Federal de Viçosa, em Viçosa, Minas Gerais, em maio de 2009. Após a lavagem em água corrente, os frutos foram imersos por cinco minutos em suspensões aquosas de fécula de mandioca a $0 ; 2 ; 3$ e 4\% (p:v) acrescidas de $0,5 \mathrm{~mL} . \mathrm{L}^{-1}$ de óleo mineral Assist (Bayer Cropscience). Os frutos foram armazenados a $21,0 \pm 1,0^{\circ} \mathrm{C}$ e umidade relativa de $85 \pm 5 \%$, por 12 dias. As amostragens foram realizadas no tempo zero (dia da montagem do experimento) e depois de quatro em quatro dias.

As variáveis avaliadas foram: perda de massa fresca, rendimento em suco e teores de sólidos solúveis, acidez titulável e ácido ascórbico. A perda de massa fresca foi determinada por gravimetria, e os resultados foram expressos em porcentagem de perda de massa, considerando-se a diferença entre o peso inicial do fruto e o obtido em cada amostragem. O rendimento (\%) foi calculado pela relação entre o peso de suco/peso do fruto. A acidez titulável foi determinada por titulação do suco com $\mathrm{NaOH}$ a $0,1 \mathrm{M}$ e expressa em porcentagem de ácido cítrico (AOAC, 1997). O teor de ácido ascórbico foi determinado por titulação com reagente de Tillman [2,6 diclorofenolindofenol (sal sódico) a 0,1\%] (AOAC, 1997), com os resultados expressos em mg. $100 \mathrm{~g}^{-1}$ de amostra. O teor de sólidos solúveis foi determinado usando refratômetro digital (AOAC, 1997).

O experimento foi conduzido em delineamento inteiramente casualizado, em parcelas subdivididas com três repetições e três frutos por unidade experimental. As parcelas foram constituídas de diferentes doses de fécula de mandioca e as subparcelas o intervalo de tempo da amostragem.

Os dados foram analisados por meio das análises de variância e regressão, utilizando o software SAEG (2007). Os modelos, ajustados por meio de regressão, foram escolhidos com base na significância dos coeficientes, a nível de $5 \%$ de probabilidade, pelo teste " $t$ ", no coeficiente de determinação e no potencial para explicar o fenômeno biológico. Independentemente da interação dose x intervalo de tempo de amostragem ser ou não significativa, optou-se pelo seu desdobramento, dado o interesse em estudo.

\section{RESULTADOS E DISCUSSÃO}

A perda de massa fresca teve ajuste linear para todos os tratamentos (Figura $1 \mathrm{~A}$ ). As maiores perdas foram registradas para os frutos da testemunha $(0 \%)$ quarto dia de avaliação, a perda de massa fresca foi de $6,54 \%$, e no $12^{\circ}$ dia de $19,62 \%$, que foram as maiores durante todo o período experimental, quando comparadas aos demais tratamentos.

Os frutos tratados com fécula de mandioca apresentaram menor perda de massa fresca, devido à formação de uma película ao redor do fruto, que age como barreira física para trocas gasosas e perda de vapor d'água, modificando a atmosfera e retardando o amadurecimento do fruto (HENRIQUE et al., 2008). Oliveira e Cereda (1999), trabalhando com frutos de goiaba 'Kumagai' de polpa branca, revestidas com filmes de fécula de mandioca a 3\% e 5\%, armazenados a $21-29^{\circ} \mathrm{C}$ e $65-83 \%$ UR observaram que os frutos recobertos com fécula apresentaram menor perda de massa que os não tratados com fécula, e se mantiveram em ótimas condições para consumo por até nove dias.

Neste trabalho, as perdas variaram de $14,41 \%$ (2\%) a $19,62 \%$ (0 \%) no $12^{\circ}$ dia de armazenamento (Figura 1). Para Chitarra e Chitarra (2005), perdas da ordem de $3 \%$ a $6 \%$ são suficientes para causar declínio na qualidade, mas alguns produtos são ainda 
comercializáveis com $10 \%$ de perda. Tomando como referência a perda de $10 \%$, os frutos do tratamento com $2 \%$ de fécula poderiam ser comercializados até o oitavo dia, enquanto os dos demais tratamentos poderiam ser comercializados até o quarto dia.

Parte da perda de massa pode ter sido causada pela redução no conteúdo de suco, pois de acordo com Chitarra e Chitarra (2005), quando a casca realiza trocas gasosas com o ambiente, o endocarpo perde suco para a casca, resultando em redução no rendimento de suco. Essa redução não seguiu o mesmo padrão da perda de massa. Todos os tratamentos apresentaram redução de rendimento, sendo que a perda pelos frutos tratados com $2 \%$ e $4 \%$ de fécula foi semelhante à do testemunha. Os frutos que receberam a aplicação de 3\% foram os que apresentaram o maior rendimento, após 12 dias (Figura $1 \mathrm{~B}$ ). Henrique e Cereda (2007) não verificaram redução no rendimento em suco de limão siciliano quando utilizaram fécula de mandioca. Uma possível explicação pode ser a sensibilidade diferencial das variedades.

Foi observado que quando se utilizaram as maiores concentrações ( 3 e 4\%), houve escurecimento da casca, descamação da película e odor desagradável, sugerindo que estas doses podem ter sido excessivas, o que pode ter causado toxidez que se manifestou através de manchas amarronzadas nos frutos, e pode induzir a ocorrência de processo fermentativo por bactérias e leveduras. Se o revestimento for muito espesso ou possuir baixa permeabilidade a oxigênio e ao dióxido de carbono, a fruta pode respirar anaeróbicamente, sofrendo desordens fisiológicas (HENRIQUE et al., 2008).

O teor de sólidos solúveis ajustou-se ao modelo quadrático e aumentou nos frutos do testemunha $(0 \%)$, de maneira constante (Figura $1 \mathrm{C}$ ). Esta concentração de sólidos solúveis para a dose $0 \%$ pode ser explicada pela excessiva perda de massa nos frutos deste tratamento (Figura 1 A). Observa-se que quanto maiores foram as doses de fécula, menores foram os teores de sólidos solúveis, indicando que houve menores perdas de água, havendo, portanto, menor efeito de diluição.

O teor de acidez titulável nos frutos reduziu-se e se ajustou ao modelo quadrático (Figura 1 D). Frutos tratados com fécula de mandioca, na dose de $4 \%$, muito pouco a acidez durante não alteraram o tempo de armazenamento, enquanto nos frutos do testemunha ou fécula a redução foi drástica durante todo o período de armazenamento.

Os teores de ácido ascórbico ajustaram-se ao modelo quadrático (Figura $1 \mathrm{E}$ ) com redução no teor em todos os tratamentos, ao longo do período de armazenamento. No entanto, observou-se que para o testemunha $(0 \%)$ esta redução foi mais acentuada. No oitavo dia de armazenamento, o teor de ácido ascórbico nos frutos do testemunha apresentou redução de aproximadamente $70 \%$, enquanto nos frutos dos demais tratamentos ela ficou em torno de $50-60 \%$. Os resultado indicam que o biofilme de fécula de mandioca tem potencial para manter a qualidade de frutos de mexerica-do-rio durante o armazenamento, a temperatura ambiente.

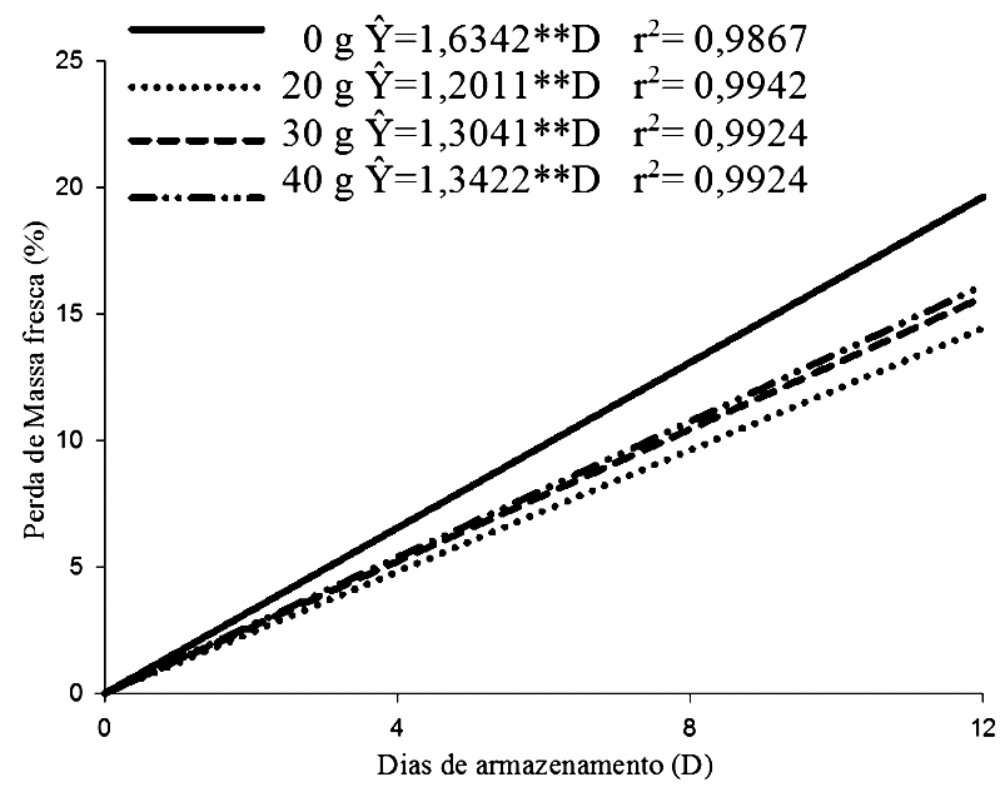

FIGURA 1- Perda de massa fresca (\%) em frutos de 'Mexerica-do-Rio' tratados com diferentes concentrações de fécula de mandioca e armazenados a $21,0^{\circ} \mathrm{C}$. 


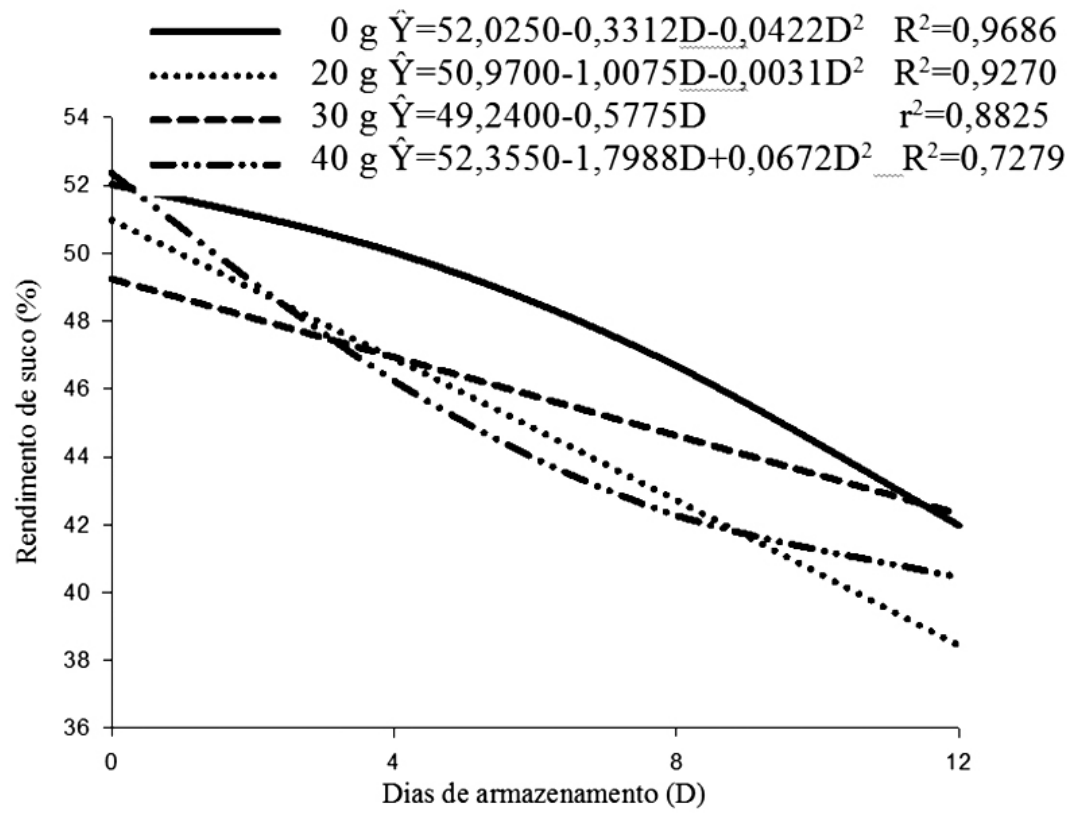

FIGURA 2 - Rendimento de suco (\%) em frutos de 'Mexerica-do-Rio' tratados com diferentes concentrações de fécula de mandioca e armazenados a $21,0^{\circ} \mathrm{C}$.

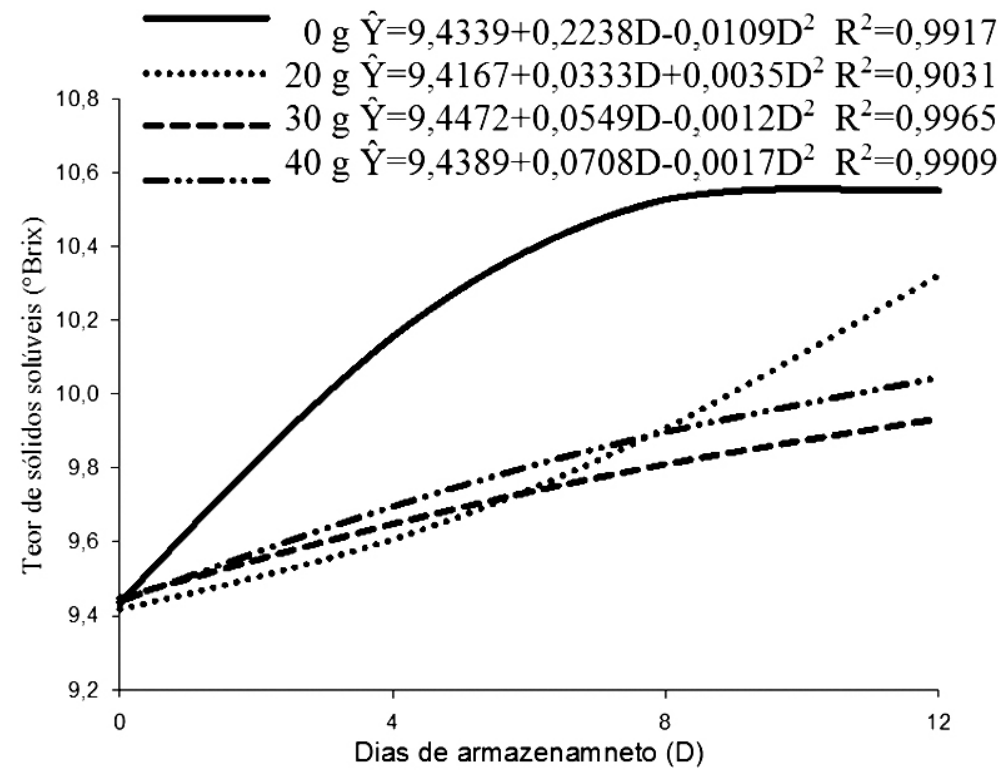

FIGURA 3 - Teor de sólidos solúveis ( ${ }^{\circ}$ Brix) no suco de frutos de 'Mexerica-do-Rio' tratados com diferentes concentrações de fécula de mandioca e armazenados a $21,0^{\circ} \mathrm{C}$. 


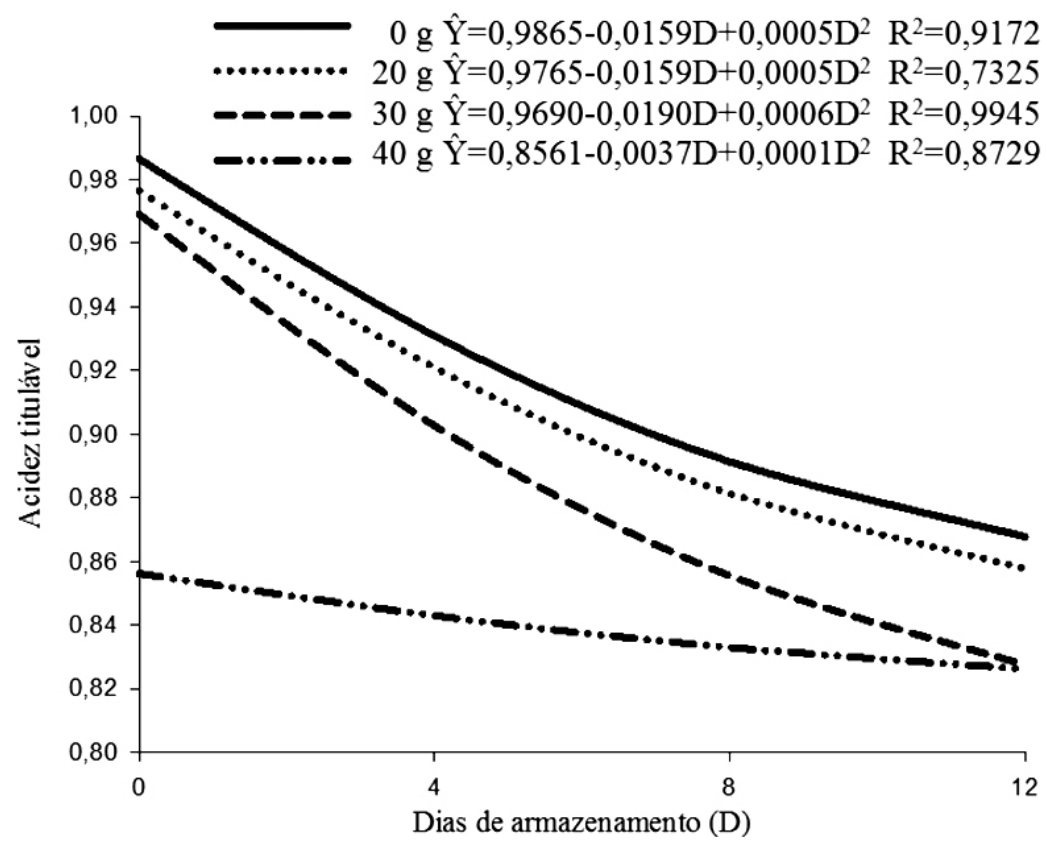

FIGURA 4 - Acidez titulável (\% de ácido cítrico) no suco de frutos de 'Mexerica-do-Rio' tratados com diferentes concentrações de fécula de mandioca e armazenados a $21,0^{\circ} \mathrm{C}$.

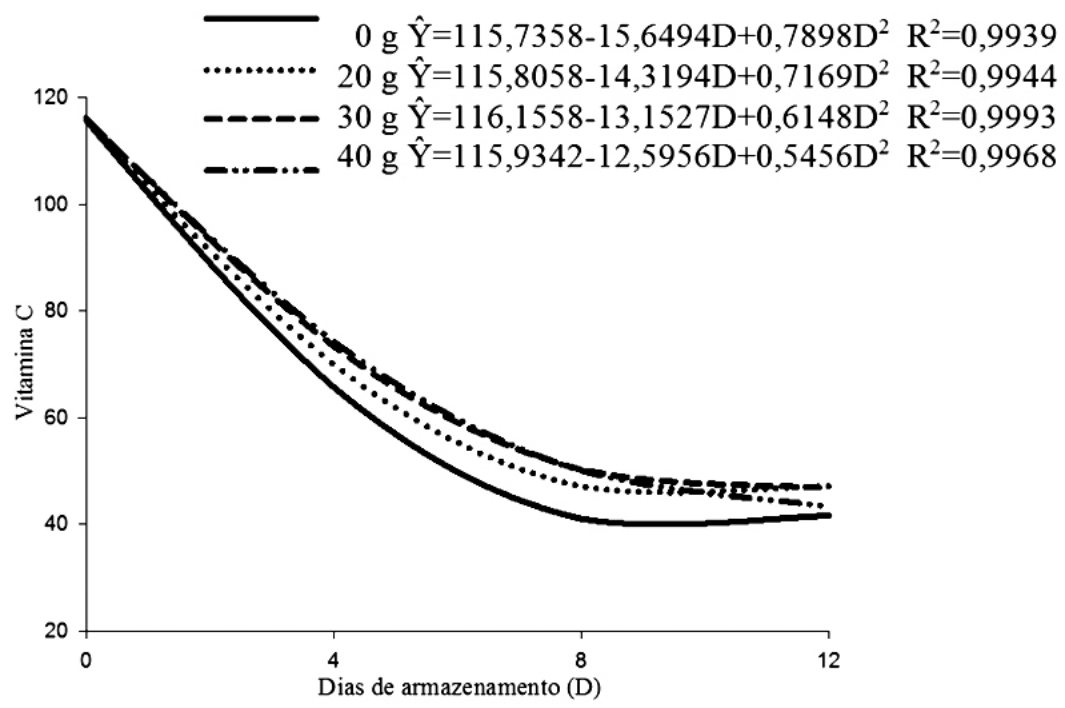

FIGURA 5 - Teor de ácido ascórbico $\left(\mathrm{mg} 100^{-1} \mathrm{~g}\right)$ no suco de frutos de 'Mexerica-do-Rio' tratados com diferentes doses de fécula de mandioca e armazenados a $21,0^{\circ} \mathrm{C}$. 


\section{CONCLUSÃO}

Frutos do tratamento-controle apresentavam-se imprestáveis para o consumo no quarto dia de armazenamento. $\mathrm{O}$ uso de biofilme foi eficiente em retardou a perda de massa dos frutos, assim como o rendimento em suco, com aumento no teor de sólidos e solúveis, redução nos de acidez titulável e conseqüente redução no de ácido ascórbico, o que permitiu estender a vida útil dos frutos, a 8 dias.

\section{REFERÊNCIAS}

AOAC. Official methods of analysis of the Association of Official Analytical Chemists International. 16th ed. Washington, 1997. v.2.

CHITARRA, M.I.F; CHITARRA, A.B. Pós-colheita de frutas e hortaliças: fisiologia e manuseio. 2.ed. Lavras: UFLA, 2005. 785 p.

HENRIQUE, C.M.; CEREDA, M.P. Uso de ethephon e fécula de mandioca na conservação pós-colheita de limão-siciliano. Revista de Biologia e Ciências da Terra, João Pessoa, v.7, n.1, p.99-106, 2007.

HENRIQUE, C.M.; CEREDA, M.P.; SARMENTO, S.B.S. Características físicas de filmes biodegradáveis produzidos a partir do amido modificado de mandioca. Ciência e Tecnologia de Alimentos, Campinas, v.28, n.1, p.231-240, 2008.

LEMOS, O.L.; REBOUÇAS, T.N.H.; JOSÉ, A.R.S.; VILA, M.T.R.; SILVA, K.S. Utilização de biofilme comestível na conservação de pimentão 'Magali R' em duas condições de armazenamento. Bragantia, Campinas, v. 66, n. 4, p. 693-699, 2007.
MACIEL, M.I.S.; LIMA, V.L.A.G.; SANTOS, E.S.; LIMA, M.S. Effects of biofilm and refrigeration on acerola postharvest conservation. Revista Brasileira de Fruticultura, Jaboticabal, v.26, n.1. p.168-170, 2004.

NASCIMENTO, E. T. do; PEREZ-MALUF, R.; GUIMARAES, R. A.; CASTELLANI, M. A. Diversidade de abelhas visitantes das flores de Citrus em pomares de laranjeira e tangerineira. Revista Brasileira de Fruticultura, Jaboticabal, v.33, n.1, p. 111-117, 2011.

NUNES, E. E.; BOAS, B. M. V.; CARVALHO, G. L. DE; SIQUEIRA, H. H. DE; LIMA, L. C. DE O. Vida útil de pêssegos 'Aurora 2' armazenados sob atmosfera modificada e refrigeração. Revista Brasileira de Fruticultura, Jaboticabal, v.26, n.3, p.438-440, 2004.

OLIVEIRA, M.; CEREDA, M.P. Pós-colheita de pêssegos (Prunus pérsica L. Bastsch) revestidos com filmes à base de amido como alternativa à cera comercial. Ciência e Tecnologia, Campinas, v.23, p.28-33, 2003

OLIVEIRA, M.A.; CEREDA, M.P. Efeito da película de mandioca na conservação de goiabas. Brazilian Journal of Food Technology, Campinas, v. 2, n. 1-2, p. 97-102, 1999.

SAEG - Sistema para análises estatísticas. Versão 9.1. Viçosa: Fundação Arthur Bernardes, 2007. SCANAVACA JÚNIOR, L. F. N.; PEREIRA, M. E. C. Uso de fécula de mandioca na pós-colheita de manga 'surpresa'. Revista Brasileira de Fruticultura, Jaboticabal, v.29, n.1, p.67-71, 2007. 